\title{
Correction to: Changes in surgicaL behaviOrs dUring the CoviD-19 pandemic. The SICE CLOUD19 Study
}

\author{
Umberto Bracale ${ }^{1} \cdot$ Mauro Podda $^{2} \cdot$ Simone Castiglioni ${ }^{1,3} \cdot$ Roberto Peltrini $^{1} \cdot$ Alberto Sartori $^{4} \cdot$ Alberto Arezzo $^{5}$. \\ Francesco Corcione ${ }^{1} \cdot$ Ferdinando Agresta $^{6} \cdot$ the CLOUD-19 Collaborative Group
}

Published online: 11 May 2021

(c) The Author(s) 2021

\section{Correction to: Updates in Surgery (2021) 73:731-744 https://doi.org/10.1007/s13304-021-01010-w}

The Collaborative Group there are two authors names are incorrect. The correct names are provided below:

Paolo Pietro Bianchi and Giampaolo Formisano

Open Access This article is licensed under a Creative Commons Attribution 4.0 International License, which permits use, sharing, adaptation, distribution and reproduction in any medium or format, as long as you give appropriate credit to the original author(s) and the source, provide a link to the Creative Commons licence, and indicate if changes were made. The images or other third party material in this article are included in the article's Creative Commons licence, unless indicated otherwise in a credit line to the material. If material is not included in the article's Creative Commons licence and your intended use is not permitted by

The original article can be found online at https://doi.org/10.1007/ s13304-021-01010-w.

Umberto Bracale

umbertobracale@gmail.com

Simone Castiglioni

simone.castiglioni90@gmail.com

1 Department of General Surgery and Specialties, University Federico II of Naples, Naples, Italy

2 Department of Emergency Surgery, Policlinico Universitario Di Monserrato, Azienda Ospedaliero-Universitaria Di Cagliari, Cagliari, Italy

3 Department of Medical, Oral and Biotechnological Sciences, University "G. D’Annunzio" Chieti-Pescara, Chieti, Italy

4 Department of General, Oncological and Metabolic Surgery, Castelfranco and Montebelluna Hospitals, Treviso, Italy

5 Department of Surgical Sciences, University of Torino, Torino, Italy

6 Department of General Surgery, Ospedale Di Vittorio Veneto, ULSS 2, Marca Trevigiana, Italy statutory regulation or exceeds the permitted use, you will need to obtain permission directly from the copyright holder. To view a copy of this licence, visit http://creativecommons. org/licenses/by/4.0/.

Publisher's Note Springer Nature remains neutral with regard to jurisdictional claims in published maps and institutional affiliations. 